\title{
Novas tendências de metropolização em cidades médias do Brasil: um estudo de caso no Estado do Rio Grande na possível Região Metropolitana de Passo Fundo - RMPF
}

\author{
New metropolization trends in medium-sized cities in Brazil: a \\ case study in the State of Rio Grande of the possible \\ Metropolitan Region of Passo Fundo - RMPF
}

Fabricio Longhi Bernardes [a] [D, Alcindo Neckel [a] [D), Henrique Aniceto Kujawa [b] [D, Laércio Stolfo Maculan [c] [D]

\author{
[a] Faculdade Meridional (IMED), Programa de Pós-graduação Strictu Sensu em Arquitetura e Urbanismo, Passo \\ Fundo, RS, Brasil \\ [b] Università di Perugia, Piazza Università, Perugia, Italia \\ [c] Faculdade Meridional (IMED), Passo Fundo, RS, Brasil
}

Como citar: Bernardes, F. L., Neckel, A., Kujawa, H. A. \& Maculan, L. S. (2021). Novas tendências de metropolização em cidades médias do Brasil: um estudo de caso no Estado do Rio Grande na possível Região Metropolitana de Passo Fundo. urbe. Revista Brasileira de Gestão Urbana, v. 13, e20200165. https://doi.org/10.1590/2275-

3369.013.e20200165

\section{Resumo}

0 projeto de metropolização em cidades médias torna-se uma nova realidade no Brasil, a medida que as políticas públicas incentivam a aprovação de projetos de lei voltados a criação de regiões metropolitanas. 0 objetivo geral da pesquisa é analisar a configuração espacial da viabilidade ou impossibilidade de metropolização da RMPF. Metodologicamente, foi analisada a configuração espacial da RMPF, por meio do método da sintaxe espacial da malha viária dos 23 municípios da RMPF. A pesquisa foi realizada com os líderes do segmento dos 23 municípios que compõem o projeto RMPF. Para coleta de dados foram entrevistados 159 líderes de segmentos (industrial, educação, saúde, bancários, empregatício e arquitetos e urbanistas), sobre a possibilidade de Passo Fundo se tornar uma metrópole. Os dados foram tratados estatisticamente pelo modelo matemático de regressão linear. Os resultados da possível Característica de Metropolização (CM) da RMPF, numa escala de 1 a 10, apresentou o valor de 4,1438, indicando que o projeto de metropolização apresenta debilidades. A constituição da metropolização em cidades médias requer mais do que um marco regulatório e condições objetivas, necessita uma construção social e política.

Palavras-chave: Metropolização. Cidades médias. Sintaxe espacial. Líderes de segmentos.

FLB é arquiteto urbanista, mestre em Arquitetura e Urbanismo, e-mail: fabriciobernardes79@gmail.com

AN é professor, doutor em Geografia, e-mail: alcindo.neckel@imed.edu.br

HAK é professor, doutor em Ciências Sociais, e-mail: henriquekujawa@gmail.com

LSM é professor, doutor em Arquitetura, e-mail: laercio.maculan@imed.edu.br 


\section{Abstract}

The metropolization project in medium-sized cities becomes a new reality in Brazil, as public policies encourage the approval of bills aimed at creating metropolitan regions. The general objective of the research is to analyze the spatial configuration of the viability or impossibility of metropolization of the RMPF. Methodologically, the spatial configuration of the RMPF was analyzed, using the method of spatial syntax of the road network of the 23 municipalities of the RMPF. The Research was carried out with the segment leaders of the 23 municipalities that make up the RMPF project. For data collection, 159 segment leaders (industrial, education, health, banking, employment and architects and urban planners) were interviewed about the possibility of Passo Fundo becoming a metropolis. The data were treated statistically by the linear regression mathematical model. The results of the possible Metropolization Characteristic (CM) of the RMPF, on a scale of 1 to 10, presented the value of 4.1438, indicating that the metropolization project presents weaknesses. The constitution of metropolization in mediumsized cities requires more than a regulatory framework and objective conditions, it requires a social and political construction.

Keywords: Metropolization. Medium cities. Spatial syntax. Segment leaders.

\section{Introdução}

O processo de metropolização é um fenômeno amplo, com algumas características de integração entre cidades, as quais formam uma região metropolitana. Além disso, há uma cidade polo que exerce o papel de sede na escala urbana e regional (Ruiz, 2015; Clout, 2020). Os estudos têm mostrado outras tendências no processo de metropolização que são capazes de modificar o capital econômico, ocasionando desequilíbrio territorial pela função de centralidade exercitada pela metrópole (Raposo et al., 2012; Martínez \& Santibáñez, 2015; Scott, 2019; Dadashpoor \& Ahani, 2019; Clout, 2020).

A metrópole se constitui num sistema social complexo, pois é composta por uma diversidade de serviços, adensamento de funções urbanas, integrações de infraestruturas físicas e matrizes econômicas (Dadashpoor \& Ahani, 2019; Teixeira et al., 2020). Esses aspectos incidem na força de trabalho, que depende, quase que exclusivamente do sistema viário, que acaba sobrecarregando a infraestrutura espacial de mobilidade metropolitana, que precisa atender na sua área territorial, a integração das funções urbanas, políticas e econômicas (Brandão, 2017; Li, Zhou \& Wen, 2019; Clout, 2020).

Historicamente, a metropolização ocorre por meio da integração da cidade de grande porte com sua estrutura funcional, com as seguintes características: a polarização exercida pela metrópole; grande intensidade de fluxo de pessoas, mercadorias e capitais; incremento das atividades de serviços; maior demanda do trabalho imaterial; concentração das atividades de gestão e administração, questões como a tecnologias da informação e comunicação; e desigualdade e segregação socioespacial (Raposo et al., 2012; Rosaneli et al., 2016; Carmo, 2017).

As cidades brasileiras, a partir da década de 1970, conforme Silva et al. (2018), começaram a discutir a implementação das regiões metropolitanas. Um marco legal importante foi a ratificação na Constituição Federal de 1988, pelo artigo 25, que legitima o poder do Estado para instituir a Região Metropolitana, mediante a projeto complementar de lei. A partir desse momento, foram propostos e implementados diversos processos de metropolização, os quais foram justificados segundo fatores, tais como, o crescimento populacional, movimentos migratórios, diversidade e complexidade do comércio e serviço, redes de tecnologias de informação, proximidades dos mercados, além da facilitação e ampliação das possibilidades de contatos regionais (Villaça, 2012; Carmo, 2017; Sá et al., 2017; Bernardes, 2018; Fuga, 2019).

Outro marco importante foi a construção do Estatuto da Metrópole, sob a Lei número 13.089, de 12 de janeiro de 2015, descritos as definições legais de aglomeração urbana, metrópole e a região metropolitana (Brasil, 2015). O Estatuto das metrópoles é marcado pelas ausências, imprecisões e contradições conceituais, por serem reiteradas pela política capitalista preponderante, dificultando a instrumentalização de políticas. Pois, a falta de hierarquia dificulta a otimização e direcionamento das ações e recursos econômicos (Peres et al., 2018; Hoshino \& Moura, 2019). 
Em relação à integração econômica regional, o processo de metropolização pode ocasionar reajustes econômicos e espaciais (Ghasemi, Hamzenejad \& Meshkini, 2018). As possíveis causas estão na adequação das estruturas de fluxos dos insumos e produtos, uma vez que, esses fatores acarretam a redistribuição da estrutura industrial e influenciam o nível de eficiência do uso e ocupação do solo (Raposo et al., 2012; Campos, 2019). Consequentemente, para Martínez \& Santibáñez (2015) e Dadon \& Oldani (2017), a metropolização tem a capacidade de influenciar o sistema regional de gestão urbana e territorial. Segundo Bernardes (2018), há uma tendência de metropolização também nas cidades médias, pois observa-se a capacidade de integração e incremento do consumo de produtos e serviços da cidade sede, em menor grau, do que as demais cidades que compõem a região metropolitana. As pequenas cidades se beneficiariam, principalmente, pela ampliação do fornecimento de produtos e pela facilitação do consumo de bens e serviços da metrópole.

Segundo Lobo, Tourinho \& Costa (2017), as cidades médias exercem relações de dependência físicofinanceira na medida que interagem com as cidades pequenas na oferta da diversificação de produtos e serviços. A integração entre as cidades pode contribuir para o crescimento e as alterações na configuração urbana, esse fenômeno vem sendo estudado por meio de análises de dispersão urbana. Da mesma forma, Ojima (2006) e Reis (2006), apontam que a dispersão urbana contribui para compreensão da organização espacial das cidades e suas diferentes transformações no espaço territorial. Segundo o IBGE (2020), as regiões metropolitanas compostas por cidades médias exprimem algumas relações e especificidades, tais como as situações de interdependência, relações de consumo, efeito da metrópole na mesorregião, e a cidade polo conta com uma população entre 100.000 e 500.000 habitantes. Para Santos (2010), cidades com mais de 100 mil habitantes tendem se tornar centros regionais de serviços.

Esta pesquisa procura avaliar a proposição da constituição da Região Metropolitana de Passo Fundo RMPF. A iniciativa foi apresentada por meio do projeto de lei complementar - PLC 18/2015, encaminhado à Assembleia Legislativa do Estado do Rio Grande do Sul. A proposta tem o objetivo "criar a Região Metropolitana de Passo Fundo - RMPF, considerando a densidade populacional e a importância econômica desta região do Estado", e contará com 23 municípios. As bases teóricas utilizadas para justificar a proposição do projeto complementar de lei foram a conceituação de Região Metropolitana segundo o IBGE e o artigo 25 da Constituição Federal. Em razão disso, chegou-se ao seguinte problema de pesquisa: quais são os fatores que justificariam a configuração de uma região metropolitana e em que medida atendem às diretrizes estabelecidas pelo Estatuto da Metrópole, em relação à viabilidade de Passo Fundo (cidade média), tornar-se metrópole?

O objetivo geral do manuscrito é analisar a configuração espacial, avaliando a possibilidade de metropolização, considerando Passo Fundo como possível metrópole. Especificamente, o desenvolvimento desta pesquisa foi norteada pelas seguintes ações: contextualização regional que Passo Fundo exerce nas atividades econômicas (produtos industriais, educação, saúde, serviços bancários, comércio e empregos); e a realização de entrevistas com líderes de cada segmento dos 23 municípios que compõem o recorte espacial, em relação à possibilidade de Passo Fundo tornar-se metrópole; e a aplicação do modelo matemático de Regressão Linear na avaliação, com a análise dos resultados coletados durante a pesquisa.

0 artigo aponta as potencialidades da possível metropolização de cidades médias. Clementino \& Almeida (2015), Dadon \& Oldani (2017), Sá et al. (2017), Bernardes (2018), Dadashpoor \& Ahani (2019), Teixeira et al. (2020), Clout (2020), que salientam a necessidade de pesquisas em regiões metropolitanas, com a possibilidade de identificação das fragilidades e benefícios, em relação as novas tendências de metropolização de cidades médias para serem consideradas na gestão urbana do território.

\section{Metodologia}

O estudo contempla os 23 municípios integrantes do projeto de Lei complementar no 18/2015, pertencentes à área de abrangência da possível RMPF, que totaliza uma área de $6.779 .250 \mathrm{~km}^{2}$, com 341.165 habitantes (IBGE, 2018). A cidade de Passo Fundo conta com área de $783.421 \mathrm{~km}^{2}$ de território, com 
população estimada de 198.899 habitantes em 2020, com densidade demográfica de 251,13 hab./km², distribuídos em 61.808 domicílios particulares (IBGE, 2020), onde se distancia $298 \mathrm{~km}$ da área de metropolização de Porto Alegre/RS (Figura 1).

A BR-285 exerce a função regional de conectar a região de Passo Fundo, com as BR-116 e BR-101, que por sua vez estruturam as conexões entre as metrópoles litorâneas. A BR-285 conecta a região à Argentina e ao Mercosul. A ERS-324 e a BR-386 conecta-se à possível RMPF, às aglomerações urbanas da Serra Gaúcha e Porto Alegre (Maculan \& Tângari, 2020).
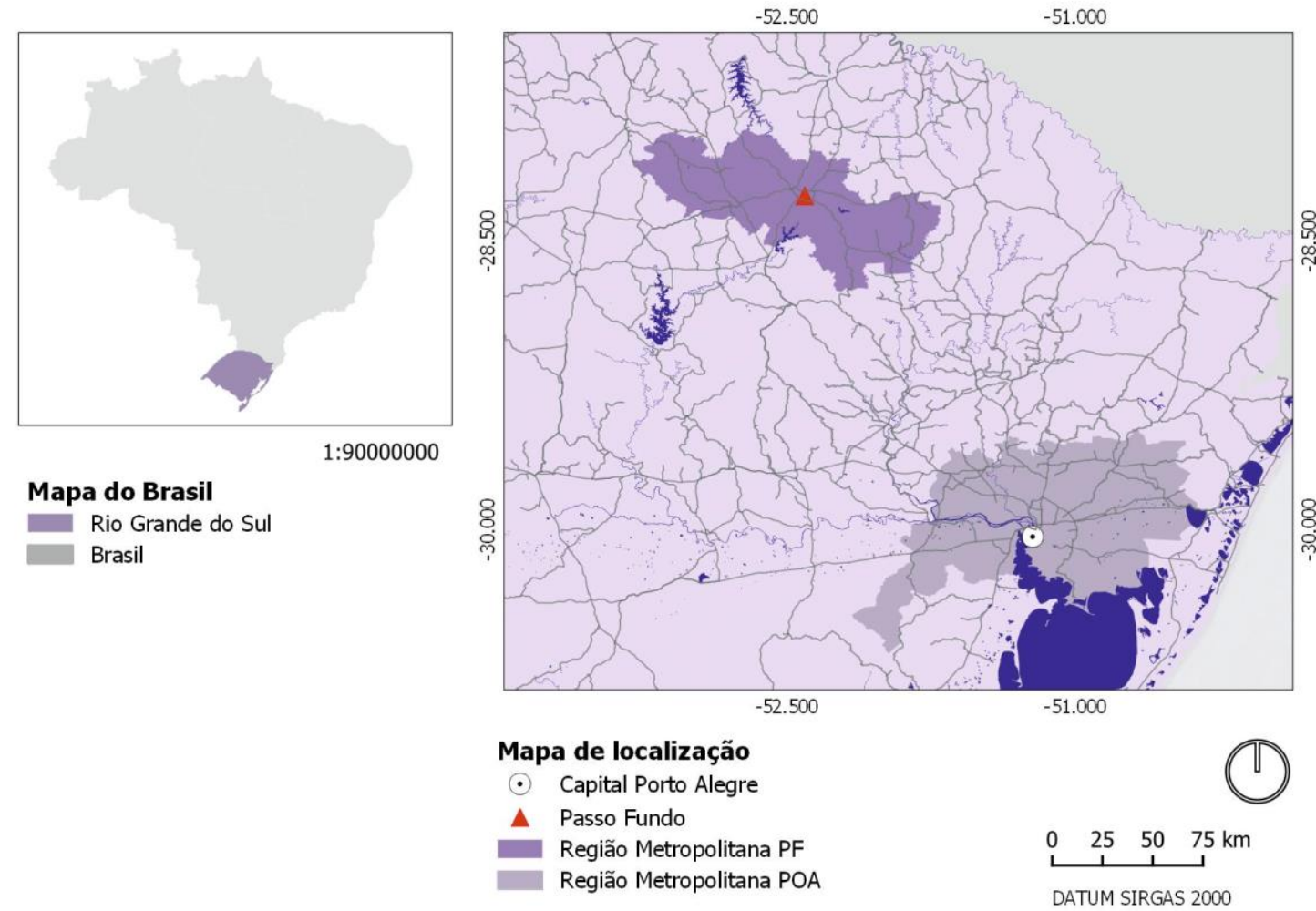

Figura 1 - Mapa de localização do território brasileiro em relação à possível Região Metropolitana de Passo Fundo - RMPF. Fonte: Elaborado a partir da base de dados do IBGE (2020).

Na Figura 2 observa-se o recorte espacial, considerando a cidade de Passo Fundo como possível metrópole, e os 23 municípios elencados no projeto de Lei Complementar no 18/2015, estes sendo: Almirante Tamandaré do Sul, Camargo, Carazinho, Casca, Chapada, Ciríaco, Coxilha, Coqueiros do Sul, David Canabarro, Ernestina, Gentil, Marau, Mato Castelhano, Muliterno, Nova Alvorada, Nova Boa Vista, Passo Fundo, Pontão, São Domingos do Sul, Santo Antônio do Palma, Santo Antônio do Planalto, Vanini e Vila Maria. 


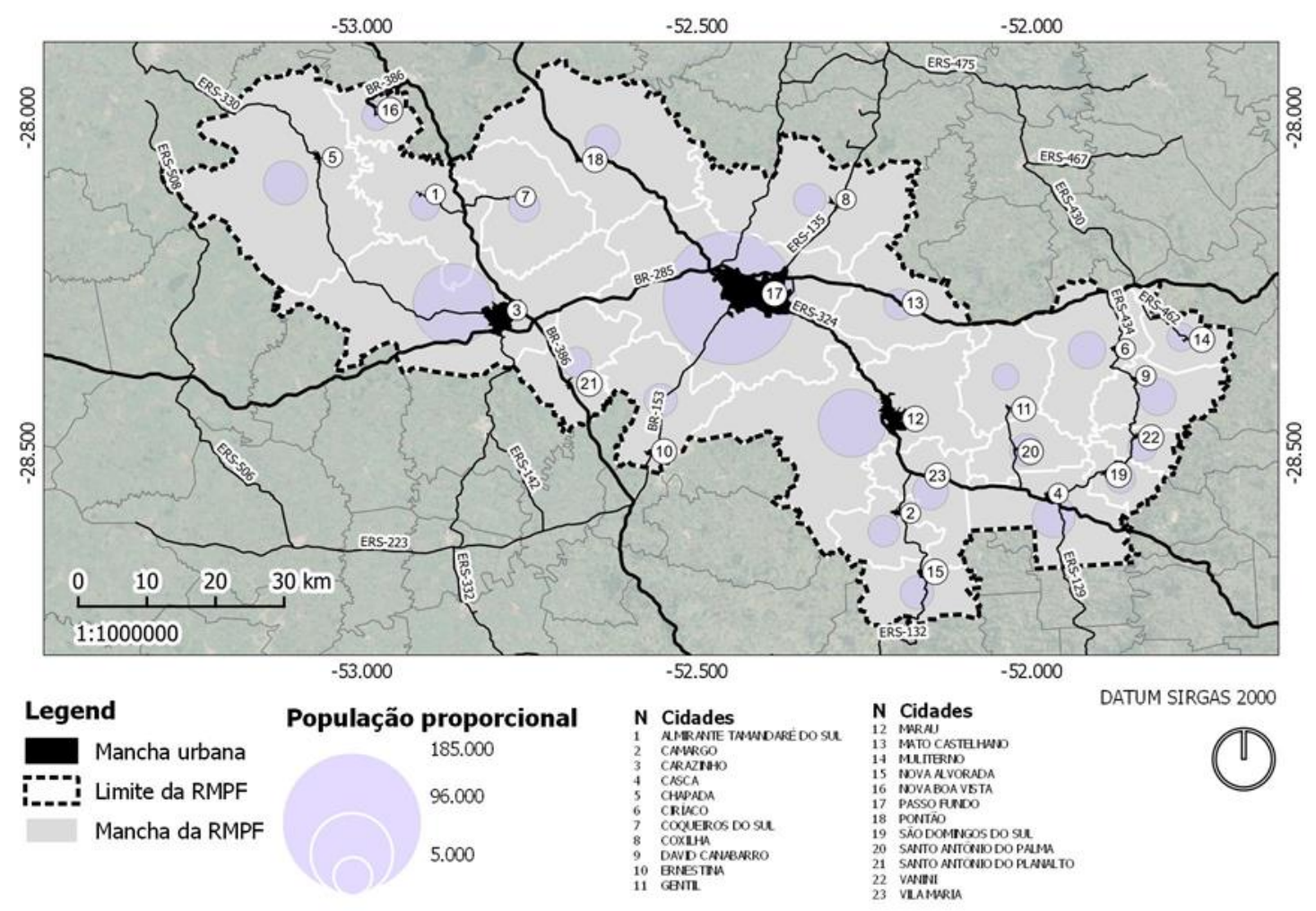

Figura 2 - Mapa geopolítico da possível Região Metropolitana de Passo Fundo - RMPF. Fonte: Elaborado da base de dados do IBGE (2020), sobrepostas nas imagens de satélite, Landsat 5 do mês de novembro de 2018, no Sensor TM (USGS, 2018).

O delineamento metodológico foi estruturado em duas etapas de análise: a configuração espacial e a percepção dos líderes de segmentos a respeito da constituição da possível RMPF:

a) configuração espacial com o uso da Sintaxe Espacial: essa teoria foi proposta por Bill Hillier na Bartlett School of Graduate Studies de Londres, no final da década de 1970, se caracteriza, como: The social logic of space, possibilitando analisar os deslocamentos naturais sobre a lógica da sociedade, pelas formas de movimento dentro de um recorte espacial (Hillier, 2007; Karimi, 2017; Fuga, 2019). Neste caso, considerou-se a possível RMPF na análise da malha viária dos 23 municípios. Utilizou-se imagens de satélites do mês de novembro de 2018, justificada pela ausência de nuvens, facilitando a visualização dos elementos físicos (sistema viário) representados na imagem (Corazza, Neckel \& Cambrussi, 2018). As imagens foram classificadas pelo método não supervisionado (segmentação com valor 8 de similaridade e 16 pixels de área, algoritmo ISOGEG, com limiar de aceitação de 99,9\%) com a união das bandas RGB543 do satélite, Landsat 5 (Sensor TM), obtidas do USGS United States Geological Survey (2018) e processadas no software Spring, versão 5.2.

Para o delineamento dos traçados e a confecção dos mapas de linhas axiais foram adotados os seguintes procedimentos: foi utilizado como base a rede viária. A atividade foi desenvolvida em Autocad e o arquivo salvo em extensão DXF (Drawing Exchange Format). A posteriori, o arquivo de linhas foi importado, segundo Srinurak \& Mishima (2017), para o software DepthmapX, onde foi utilizado os passos topológicos (n) igual a 20, na análise dos mapas de segmentos da estruturação urbana e da rede viária da região. A caracterização dos centros e das propriedades espaciais de conectividade e integração global foram gerados a partir dos mapas axiais (Zhu et al., 2017).

Para compreensão dos mapas de espacialidade e centralidades, a representação foi realizada por meio de escala cromática da sintaxe espacial. Segundo Zhu et al. (2017), Srinurak \& Mishima (2017), Jayasinghe, Sano \& Rattanaporn (2017), uma escala cromática, passando pelas cores mais quentes (próximas do vermelho) e chegando até as cores mais frias (próximas do azul). 0 vermelho são as linhas mais rasas do sistema, representando os maiores valores de integração, e o azul são as linhas mais profundas do sistema e representam os locais mais segregados (Hillier, 2007; Karimi, 2017; Fuga, 2019).

b) Opinião dos líderes dos segmentos sobre o projeto de metropolização, pelo qual Passo Fundo poderia tornar-se metrópole: a escolha dos segmentos seguiu as variáveis estabelecidas pelo Estatuto da Metrópole 
(Brasil, 2015), porém, foi preciso fazer adaptações para o contexto desse estudo, assim sendo, os setores analisados foram industriais, educação, saúde, serviços bancários, comércio, empregos e arquitetos e urbanistas dos 23 municípios que compõem a possível RMPF. Optou-se por acrescentar a classe dos arquitetos e urbanistas, pela sua importância na concepção das espacialidades urbanas numa óptica de metropolização e pelo papel técnico exercido nos departamentos de planejamento das prefeituras. Foram entrevistados 159 líderes de segmentos, os quais foram distribuídos na possível RMPF destacada no projeto de Lei complementar no 18/2015, e subdivididos da seguinte forma: 19 entrevistados no setor industrial, 24 no segmento da educação, 34 no setor de saúde, 35 no setor bancários, 8 do setor de emprego e 39 arquitetos e urbanistas com lideranças no planejamento e gestão urbana das prefeituras que poderão compor a RMPF. A seleção dos respondentes foi determinada segundo o perfil, o qual foi definido ao se considerar o cargo de gestão e o nível de conhecimento acerca do projeto de lei da RMPF.

O instrumento de coleta foi construído com base na estruturação sugerida por Bardin (2016) e Jaeger et al. (2017), que apontam para a necessidade de perguntas semiestruturadas. Ao utilizar instrumentos voltados à investigação e análise, que se baseiam nas percepções dos diferentes entrevistados. Assim, foi possível construir um arcabouço robusto estatisticamente, capaz de contribuir para a compreensão cognitiva da sociedade civil e dos técnicos que estão inseridos no recorte espacial, relacionados com a temática da metropolização. Segundo Grub e Neckel (2015), Meyer (2017), as pessoas costumam observar e relatar os processos e dinâmicas urbanas. Neckel (2014), Grub e Neckel (2015) conceituam percepção, exposta na opinião do entrevistado, como sendo o ato de concepção material e imaterial do ambiente em que o indivíduo se encontra inserido.

Para construção do instrumento de coleta de dados utilizou-se o Método de Preferência Declarada (MPD), por meio de entrevistas semiestruturas, para a ordenação das alternativas (ranking), que contenham alternativas simultaneamente apresentadas aos entrevistados com o objetivo de colocá-las em ordem de preferência (Jaeger et al., 2017). Para compreensão das percepções dos líderes de segmento, os dados coletados das opiniões dos entrevistados foram submetidos a uma modelagem matemática de regressão linear, para apresentar pontos negativos e positivos dos dados amostrados, em relação ao projeto de metropolização da RMPF (Neckel, 2014; Bardin, 2016; Lansdall-Welfare et al., 2017). Segundo Nunes (2016), Prunzel et al. (2016), Wang, Zhang \& Zheng (2019), o modelo de regressão linear é a soma de várias técnicas estatísticas utilizadas, a fim de construir um modelo matemático em que foram descritas as relações das variáveis (fatores), acerca das respostas provindas dos questionários aplicados aos líderes de segmentos.

A tabulação destes dados quantitativos, cujos valores foram representados em planilha do Excel (banco de dados), com o auxílio do software Statistical Package for the Social Sciences (SPSS), versão 22, por meio de análise da estatística descritiva, distribuição de frequência simples e cruzamento dos dados, e por softwares de acesso livre, realizou-se o Modelo de Regressão Linear com o nível de confiabilidade de 0,05. Assim foi gerado um primeiro Modelo de Regressão Linear, com 10 variáveis (X Dummy e X Discreta, com "Não" para 0 (Zero) e "Sim" para $1(\mathrm{Um})$ ), a fim de identificar quais variáveis possuem maior influência na regressão, no segundo momento, foi aplicado novamente o Modelo de Regressão Linear, em que foram consideradas cinco variáveis de maior confiabilidade, para a geração de um índice de avaliação da metropolização, com significância de 1 (menor) a 10 (maior) de importância (Wang, Zhang \& Zheng, 2019).

\section{Resultados e discussōes}

\section{Espacialidades da área configurada no projeto da RMPF}

O comércio inicial da região configurada no projeto da RMPF, se intensificou em meados do século XIX com a condução de bovinos e mulas para Sorocaba (SP-Brasil) e o transporte da erva-mate para o Uruguai e o Rio da Prata, além da exportação de pedras ágatas para a Alemanha (Tedesco, 2002; Bernardes, 2018). A Figura 3 destaca o início da rota comercial passando pela possível RMPF em 1847 (Tedesco, 2002; Batistella \& Knack, 2007; Bernardes, 2018). 


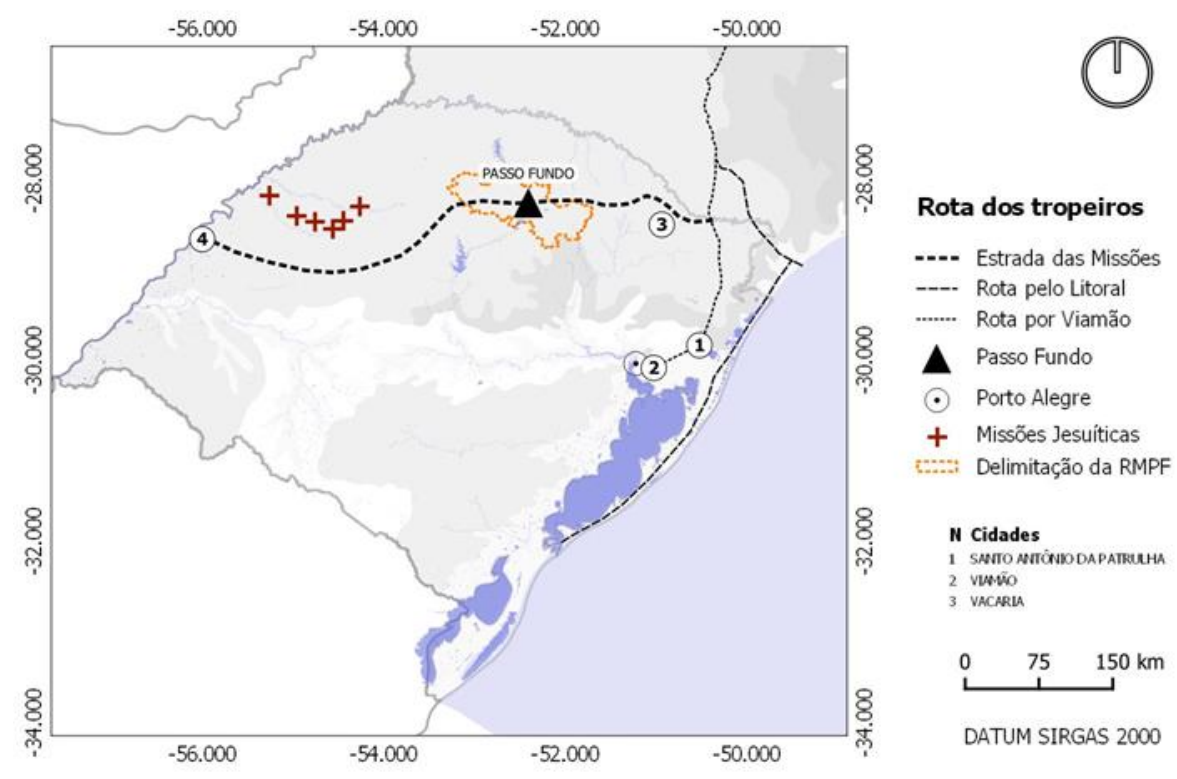

Figura 3 - Rotas comerciais de 1847 passando pela possível RMPF destacada na PLC 18/2015. Fonte: Adaptado de Tedesco (2002), Batistella \& Knack (2007), Bernardes (2018), com a utilização da base de dados do IBGE (2018).

A partir da década de 1960 a região de Passo Fundo caracteriza-se por ter mais população em áreas urbanas, consequência da carência da mão de obra para o setor industrial. Este setor industrial tornou-se responsável por transformar a matéria-prima em produto (Rückert, 2007). Segundo Rückert (2007) e Bernardes (2018), os silos de Passo Fundo recebiam grãos de municípios vizinhos, tendo a responsabilidade de escoá-los até os portos para exportação. Passo Fundo se destacava no papel de cidade central, tendo em vista seu território administrativo no primeiro ato de emancipação, que abrangia grande parte dos municípios que hoje compõem a RMPF (Kujawa, 1998).

Nesse contexto histórico, percebe-se que a configuração de interdependência entre os municípios e a centralidade exercida por Passo Fundo, que ocupa o papel de cidade de passagem, interligando e desenvolvendo muitas cidades ao seu redor. 0 município, atualmente, é considerado a capital do planalto médio e centro de referência em saúde, educação e serviços (Rückert, 2007). Para Maculan \& Tângari (2020), a região que corresponde o projeto da RMPF é caracterizada pela matriz econômica do agronegócio.

O contexto regional do projeto da RMPF é marcado pela presença de pequenas e médias cidades que apresentam algumas características em comum: a baixa diversidade de emprego; grande parte das atividades econômicas estão relacionadas a produção de commodities; as taxas de escolaridade são baixas se comparadas a média estadual; e, são altos os índices de empregabilidade voltados ao agronegócio (Maculan \& Tângari, 2020). Os principais efeitos esperados são o incremento da polarização de Passo Fundo para as cidades menores, que de acordo com Dadashpoor \& Ahani (2019), Clout (2020) podem ocasionar tendências elevadas ao desequilíbrio e desigualdades regionais.

Assim, percebe-se a importância de Passo Fundo para a história regional e na configuração geopolítica. Contata-se, nesta pesquisa, que a região da possível RMPF, em 1857 (momento da elevação econômica de Passo Fundo, na condição de Município), fazia parte do território de Passo Fundo e a metropolização pode resgatar uma antiga configuração espacial do territorial.

A análise busca compreender a capacidade de interação e conectividade física das cidades que compõem o projeto da RMPF. Com a possível criação da RMPF, Passo Fundo se tornaria metrópole. Uma possível consequência seria o incremento de incentivos fiscais para a metrópole (IBGE, 2008). Isso poderia gerar o desenvolvimento regional e o fortalecimento público-privado, com investimentos nos segmentos de produtos industriais, educação, saúde, serviços bancários, comércio e empregos (Brasil, 2015). A partir do traçado da malha viária e das linhas axial foi analisada a Integração Global da RMPF, por meio dela se verificou a existência de um núcleo central em Passo Fundo. A partir do ponto central a cidade de Passo Fundo, foram traçadas de três circunferências, sendo a primeira com raio de $50 \mathrm{~km}$, a segunda com raio de $75 \mathrm{~km}$ e a terceira com raio de 100 km, possibilitando a leitura de integração das 23 cidades relacionadas no projeto de lei da RMPF (Figura 4). 

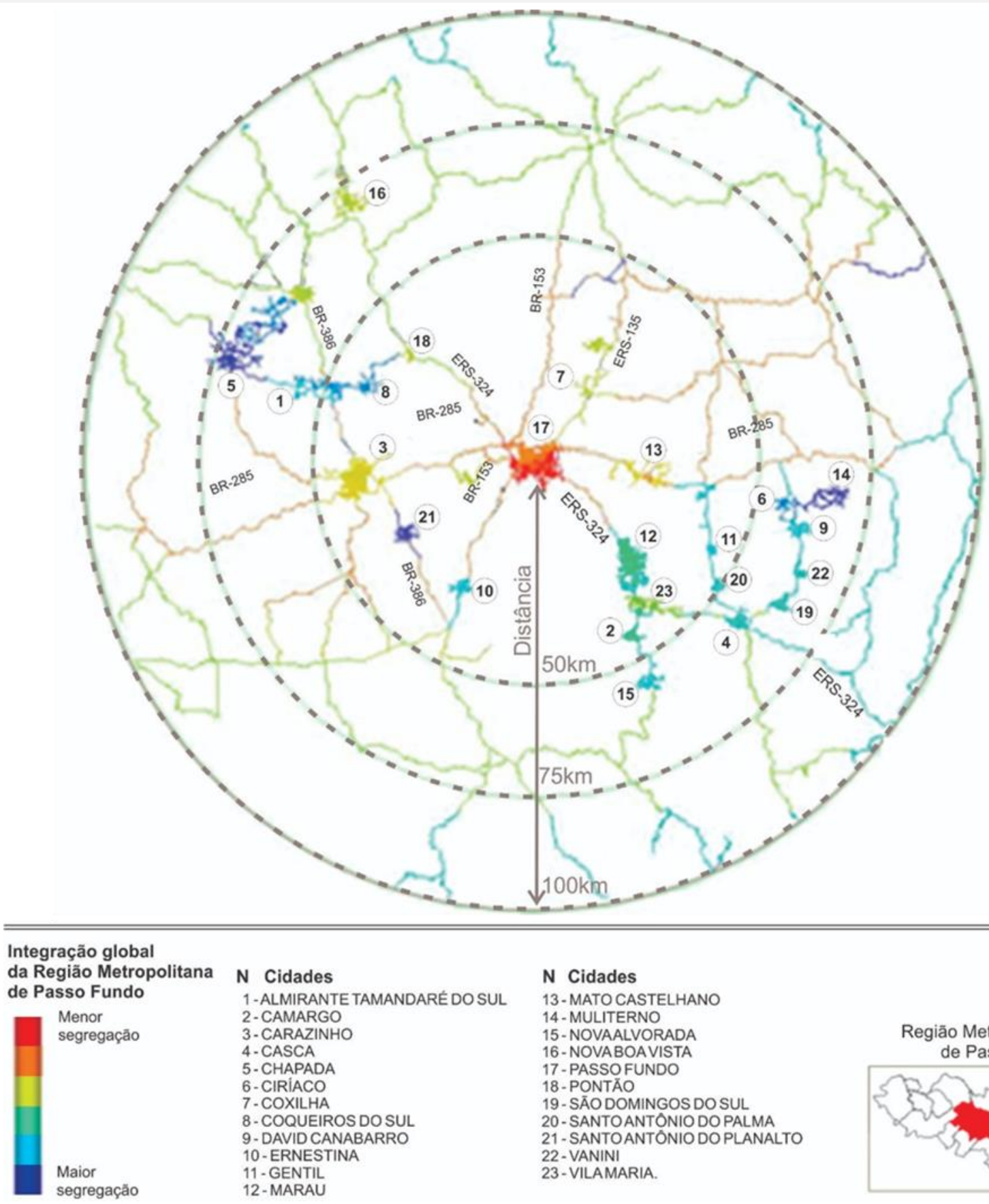

$N$ Cidades

13-MATO CASTELHANO

14 - MULITERNO

15- NOVAALVORADA

16-NOVABOAVISTA

17 - PASSO FUNDO

18-PONTÃO

19-SÃODOMINGOSDOSUL

20-SANTOANTONIODOPALMA

21 - SANTOANTONIODOPLANALTO

22. VANINI

23. VILAMARIA.

Figura 4 - Mapa axial de Integração Global das 23 cidades que compõem o projeto de lei da RMPF. Fonte: Base de dados do IBGE (2018), sobrepostas nas imagens de satélite, Landsat 5 do mês de novembro de 2018 (RGB543 - Sensor TM) (USGS, 2018).

No raio de $50 \mathrm{~km}$, pode-se observar a variação das cores quentes (tons de laranja), a Oeste o município de Carazinho (3) e a Leste de Mato Castelhano (13), que demonstram um alto grau de integração. A Sudoeste, encontram-se Marau (12), Vila Maria (23), Casca (4), Gentil e Santo Antônio do Palma (20), que obtiveram baixos valores de integração, tornando-as menos integrada a metrópole, que seria Passo Fundo.

Ao analisar as cidades localizadas entre os raios de $50 \mathrm{~km}$ e $75 \mathrm{~km}$, observam-se valores baixos de Integração global em relação à centralidade de Passo Fundo. Nova Alvorada (15), Casca (4), São Domingos do Sul (19), Vanini (22), David Canabarro (9), Muliterno (14) e Ciríaco (6) demonstraram maior segregação. Além disso, ao ultrapassarem o raio de $75 \mathrm{~km}$ de distância, supondo-se que Passo Fundo se torne a metrópole, as cidades que estejam nessas localizações podem apresentar dificuldades de acesso e, consequentemente, não usufruir dos benefícios que a metrópole pode acarretar (Bernardes, 2018; Clout, 2020).

A Figura 5 apresenta o mapa axial de conectividade, onde se observa que a região Sudeste de Passo Fundo (17) e parte do município de Marau (12) apresentam alta conectividade. Importante salientar que os 
municípios de Mato Castelhano (13) e Coxilha (8) apresentam conectividade média. Os demais municípios que compõem a RMPF apresentam conectividade fraca, o que significa a dificuldade de acesso e, consequentemente, a efetivação do projeto de lei de metropolização.

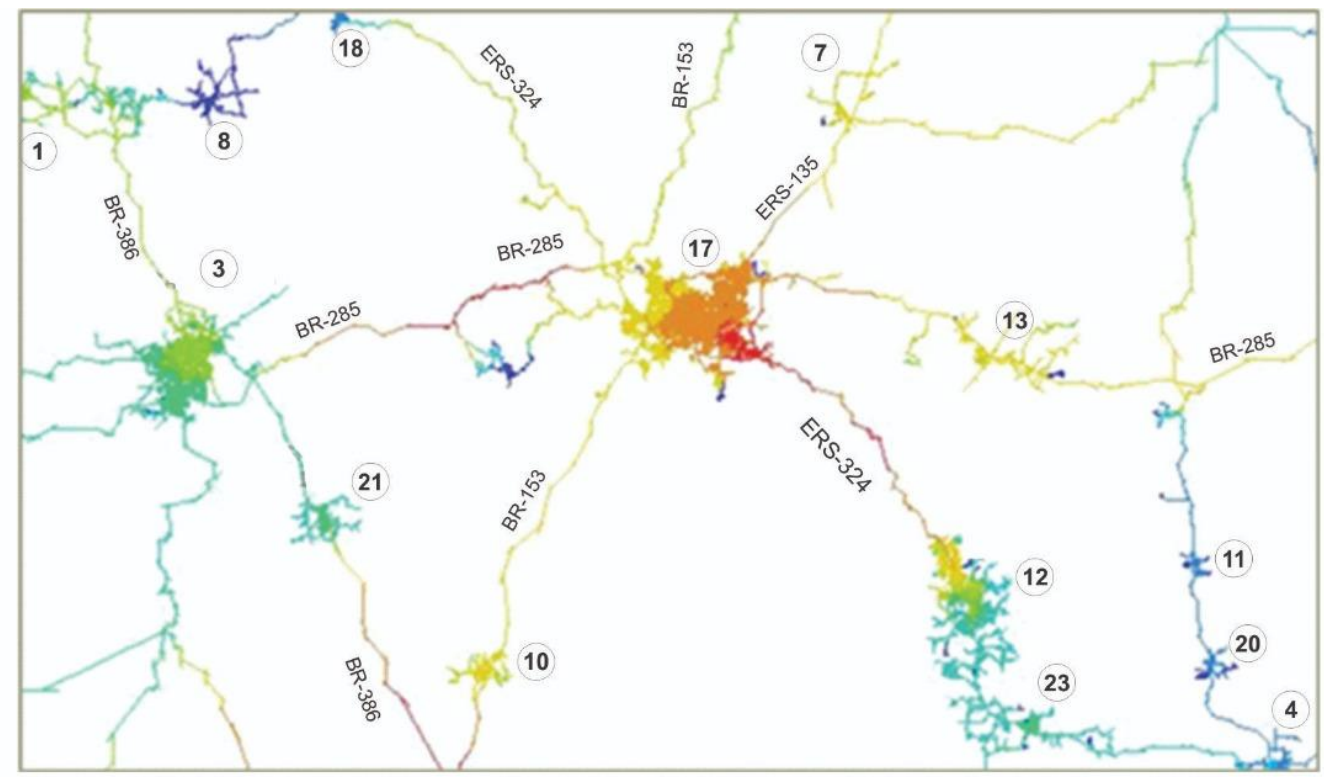

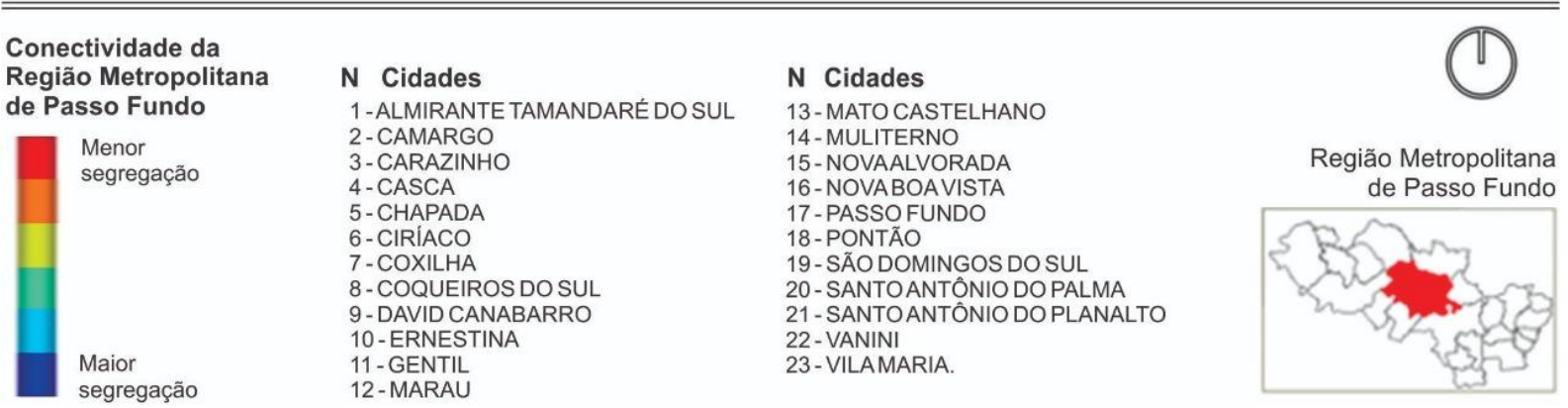

Figura 5 - Mapa Axial de Conectividade dos 23 municípios que compõem o projeto da possível RMPF. Fonte: Base de dados do IBGE (2018), sobrepostas nas imagens de satélite, Landsat 5 do mês de novembro de 2018 (RGB543 - Sensor TM) (USGS, 2018).

Convém ressaltar que Marau (12), na leitura da Integração Global em relação a todo o sistema viário, representou uma integração de média baixa com o núcleo central de Passo Fundo (17). Porém, no Mapa Axial de Conectividade, demonstra cores mais quentes, representado a alta conectividade com o núcleo central. Esses dados podem ser reforçados pela reconhecida movimentação de bens e de serviços que interligam diariamente Marau (12) e Passo Fundo (17).

Os resultados apontam desigualdades entre as cidades que compõem o projeto da RMPF em relação à integração global e à conectividade. Ossandón et al. (2013), Bernardes (2018), Dadashpoor \& Ahani (2019), e Clout (2020), destacam que os municípios que compõem uma região metropolitana, geralmente apresentam desequilíbrios em relação a prestação de serviços, que necessitam de políticas de planejamento e gestão urbana.

\section{Opinião dos líderes de segmento em relação à possibilidade de Passo Fundo se tornar metrópole}

A opinião dos líderes de segmento foi obtida por meio de 159 entrevistados e o perfil foi determinado pela faixa etária (a), escolaridade (b), faixa salarial (c) e sexo (d), conforme a Figura 6. No setor industrial foram realizadas 19 entrevistas, onde 36,84\% possuem idades entre 31 a 40 anos; 42,10\% são pósgraduados; $47,36 \%$ apresenta base salarial acima de 5 salários; $47,37 \%$ são masculinos e $52,63 \%$ femininos. 
Observa-se que a grande maioria dos entrevistados são qualificados em relação à formação técnica para assumir cargos de gestão no setor industrial.
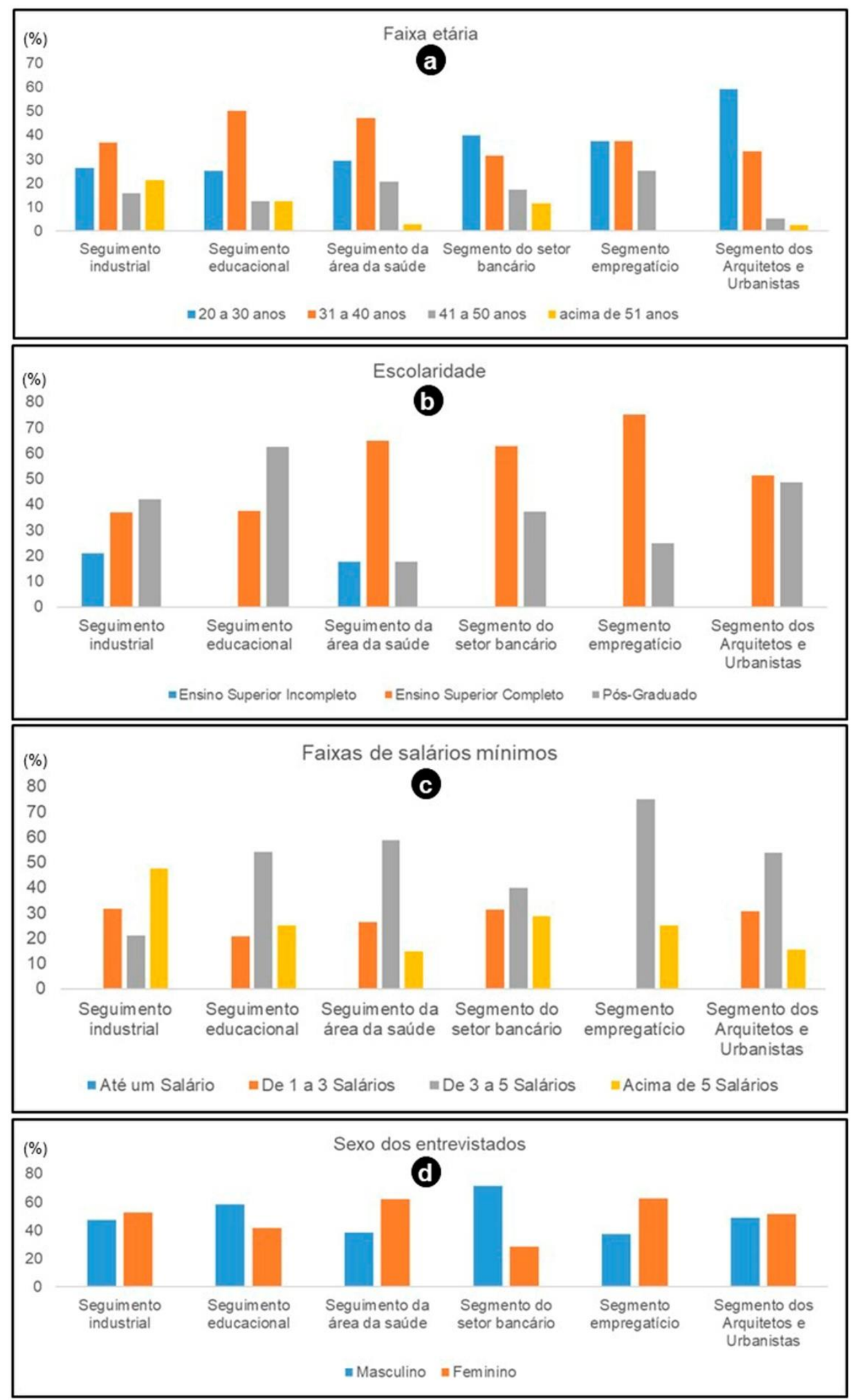

Figura 6 - Perfil dos líderes de seguimento entrevistados nos 23 municípios da possível RMPF. Fontes: Dados dos entrevistados tabulados pelos autores (2020). 
Os 24 líderes de segmento da área educacional, desses, 50\% possuem faixas etárias entre 31 a 40 anos, com grau de instrução elevado, pois $62,50 \%$ são pós-graduados, sendo que 54,16\% possuem renda entre 3 a 5 salários. E, 58,34\% dos entrevistados são masculinos e 41,66\% femininos. Na área da saúde, dos 34 indivíduos abordados, a maioria possui de 31 a 40 anos, 64,70\% ensino superior completo, 58,82\% renda de 3 a 5 salários mínimos, 38,24\% são masculinos e 61,76\% femininos. Dos 35 líderes de segmento das agências bancárias, $40 \%$ possuem 20 a 30 anos, $62,85 \%$ com ensino médio, $40 \%$ concentram renda entre 3 a 5 salários mínimos, 71,43\% são masculinos e 28,57\% femininos. No setor empregatício, dos 8 entrevistados, $37,50 \%$ possuem faixas etárias entre 20 a 30 e 31 a 40 anos, $75 \%$ possuem o ensino médio completo e renda de 3 a 5 salários, 37,50\% masculinos e 62,50\% femininos. Quanto aos 39 Arquitetos e Urbanistas, 58,97\% possui faixa etária entre 20 a 40 anos. Percebe-se em relação a escolaridade que após a graduação em Arquitetura e Urbanismo, 48,72\% não se especializaram, e 53,85\% possuem renda entre 3 a 5 Salários, 48,72\% são masculinos e 51,28\% femininos (Figura 6).

A análise da opinião dos líderes de segmento, em relação à possibilidade de metropolização da região de Passo Fundo, ocorreu após a coleta e tratamento estatístico dos dados por meio do modelo de regressão linear. Na primeira etapa utilizou-se os 159 questionários, e as 10 variáveis acerca do perfil dos líderes de segmento da possível RMPF: cargo de gestão, gênero, conhecimento de metropolização, idade, tempo de profissão, renda entre $R \$ 2.365,00$ a $R \$ 3.940,00$, renda entre $R \$ 3.941,00$ a $R \$ 8.668,00$, renda superior a $\mathrm{R} \$ 8.668,00$, superior completo e pós-graduação. Para a regressão foram atribuídos os cinco fatores de importância para as respostas sendo de 1 a 5, e, respectivamente as respostas eram: discorda totalmente, discorda em parte, nem concorda nem discorda, concorda em parte e concorda totalmente. Foi utilizado um P-valor de 95\%. As variáveis foram divididas em exploratória e discretas. As variáveis exploratórias, consistem-se em: cargo de gestão, sexo, conhecimento de metropolização, renda entre $\mathrm{R} \$ 2.365,00$ a $R \$ 3.940,00$, renda entre $R \$ 3.941,00$ a $R \$ 8.668,00$, renda superior a $R \$ 8.668,00$, superior completo, pósgraduação. E as variáveis discretas são: idade e tempo de profissão.

A Tabela 1, representa a regressão linear com todas as 10 variáveis (X Dummy e X Discreta), a fim de identificar quais variáveis possuem uma maior influência na regressão (Wang, Zhang \& Zheng, 2019).

Tabela 1 - Regressão Linear das opiniões dos 156 líderes de seguimentos entrevistados em relação às 10 variáveis de $X$

\begin{tabular}{|c|c|c|c|c|c|}
\hline $\begin{array}{l}\text { Descrição dos perfis dos } \\
\text { Líderes de segmento }\end{array}$ & Coeficientes & Erro padrão & Valor-P & $\begin{array}{l}95 \% \\
\text { inferiores }\end{array}$ & $\begin{array}{l}95 \% \\
\text { superiores }\end{array}$ \\
\hline Interseção & 0 & - & Resposta CM & Resultados & Resultados \\
\hline$X_{1}$ - Cargo de gestão & $-0,092044822$ & 0,203986533 & 0,652493368 & $-0,49519272$ & 0,311103075 \\
\hline$x_{2}-\operatorname{SexO}$ & $-0,095938776$ & 0,199303284 & 0,63097369 & $-0,489830956$ & 0,297953404 \\
\hline $\begin{array}{l}\text { X3 - Conhecimento de } \\
\text { Metropolização }\end{array}$ & 0,254064887 & 0,194801642 & 0,194209743 & $-0,130930492$ & 0,639060265 \\
\hline $\mathrm{X}_{4}$ - Idade & 0,077675047 & 0,012900699 & $1,34026 \mathrm{E}-08$ & 0,052178807 & 0,103171288 \\
\hline$X_{5}$ - Tempo de Profissão & $-0,023459215$ & 0,016019051 & 0,145218988 & $-0,055118397$ & 0,008199966 \\
\hline $\begin{array}{l}X_{6} \text { - Renda entre } R \$ 2.365,00 \\
\text { a } R \$ 3.940,00\end{array}$ & 1,167970327 & 0,304911906 & 0,000189333 & 0,565359007 & 1,770581647 \\
\hline $\begin{array}{l}X_{7} \text { - Renda entre } R \$ 3.941,00 \\
\text { a } R \$ 8.668,00\end{array}$ & 1,12367062 & 0,316474721 & 0,000517711 & 0,49820718 & 1,74913406 \\
\hline $\begin{array}{l}X_{8} \text { - Renda superior a } \\
R \$ 8.668,00\end{array}$ & 0,299404169 & 0,242641629 & 0,219209487 & $-0,180139561$ & 0,778947899 \\
\hline $\begin{array}{l}\text { X9 - Escolaridade Superior } \\
\text { Completo }\end{array}$ & 0,797890448 & 0,336619633 & 0,019080298 & 0,132613699 & 1,463167197 \\
\hline $\begin{array}{l}\text { X10- Escolaridade } \\
\text { Pós-graduação }\end{array}$ & 0,7289894447 & 0,335552404 & 0,031431148 & 0,065821912 & 1,392156982 \\
\hline
\end{tabular}

Fonte: Dados das entrevistas modeladas pelos autores (2020), e aplicadas ao modelo de regressão linear de Wang, Zhang \& Zheng (2019). 
As variáveis que apresentaram menor relevância foram: X1 - Cargo de gestão; X2 - Sexo; X3 Conhecimento de Metropolização; X5 - Tempo de Profissão; e X8 - Renda superior a R\$8.668,00. Nessas variáveis que apresentaram deficiências em relação à opinião dos entrevistados, sugere-se ao projeto de metropolização da RMPF, em que Passo Fundo poderia se tornar uma metrópole, as seguintes melhorias:

X1 - Cargo de gestão: apesar dos entrevistados possuírem cargos de gestão, as respostas indicaram que há uma série de problemas relacionados à gestão da informação referente ao projeto de lei, como a necessidade de debate com os líderes de segmento; clarificar os objetivos do projeto; a falta de divulgação por parte dos agentes públicos das especificidades do projeto; e o papel dos gestores na implantação e operacionalização do projeto. A efetiva participação comunitária nos mecanismos de gestão local poderia ser um atributo importante para concretização do projeto de metropolização. Contudo, trata-se de uma questão pouco presente na região, talvez pela característica dispersa das cidades, fator esse que dificulta a fluidez e a conexão (Ojima, Monteiro \& Nascimento, 2015).

A principal deficiência na gestão da informação, uma vez que a divulgação para a população e aos líderes de segmentos do projeto da RMPF foi deficitária. Neste sentido foi apontada a necessidade da realização de audiências públicas e também da divulgação em meios de comunicação (rádio, televisão, jornais, entre outros). Assim sendo, possibilitaria o conhecimento sobre a temática da metropolização por parte da população e segmentos, estimulando a participação coletiva para a construção do projeto de metropolização. Moura, Libardi \& Barion (2006) destacam que institucionalização de uma região metropolitana está mais relacionada com a falta de estratégias e políticas de desenvolvimento regional, do que a própria articulação regional com a população.

X2 - Sexo: a percepção do projeto de metropolização em relação à variável de gênero uma realidade presente em nossa sociedade, pois os principais apontamentos foram no sentido de garantir a importância e a valorização da mulher, seja no mercado de trabalho, bem como, nas atividades de gestão do ambiente metropolitano.

X5 - Tempo de Profissão: os entrevistados em relação ao tempo de profissão não possuem amplo conhecimento sobre o processo de metropolização da RMPF e as características da possível sede metropolitana de Passo Fundo. As experiências profissionais poderiam ser melhores utilizadas no processo, pois a experiência e a vivência poderiam ser importantes na construção de premissas do projeto de metropolização.

X8 - Renda superior a $\mathrm{R} \$$ 8.668,00: as populações de alta renda não possuem um amplo conhecimento sobre o processo de metropolização da RMPF. As camadas de alta renda tornam-se importantes na produção urbana e regional (Villaça, 2012). Porém, a população necessita de informações no processo participativo do desenvolvimento do projeto da RMPF.

Por meio da análise dos resultados apresentados na primeira regressão (Tabela 1) foi possível selecionar as variáveis de maior relevância, sendo a Variável X4 - Idade; Variável X6 - Renda entre R\$ 2.365,00 a R \$ 3.940,00; Variável X7 - Renda entre R\$ 3.941,00 a R\$ 8.668,00; Variável X9 - Escolaridade Superior Completo; e a Variável X10 - Escolaridade Pós-graduação. Foi realizada a segunda regressão linear, utilizando-se as 5 variáveis que apresentaram valores de P-valor próximo aos desejados $(0,05)$. Com isso, determinou-se o perfil adequado que se apresente $\left(\mathrm{R}^{2}\right)$ mais próximo do valor (P-valor de 95\%). Na Tabela 2 observa-se o modelo estatístico de regressão linear, gerada com o valor de R-quadrado $\left(R^{2}\right)$ de 0,9344 , o que significa que o modelo de regressão linear utilizado se aproxima dos resultados experimentais desejados (Wang, Zhang \& Zheng, 2019). A relação entre a variável dependente (CM) e as vareáveis independentes (X1...), representam o fenômeno de metropolização da RMPF e Passo Fundo como possível metrópole, sendo que essas variáveis independentes $(\mathrm{X})$ influenciam significativamente na variável CM, com um percentual de $93 \%$ de confiabilidade nos resultados.

A Característica de Metropolização (CM) de Passo Fundo com possível metrópole fundamenta-se com maior concordância de confiabilidade em relação à idade dos entrevistados (Valor-P de 1,34E-08). Percebese que os entrevistados que possuem maior faixa etária atribuem mais importância ao projeto de 
metropolização. Isso possibilita inferir que, conforme a idade dos entrevistados, atribui-se à cidade de Passo Fundo a característica de poder se tornar uma metrópole.

Tabela 2 - Regressão linear com as 5 variáveis que apresentaram um maior valor de importância.

\begin{tabular}{|c|c|c|c|c|c|}
\hline $\begin{array}{l}\text { Descrição dos perfis dos } \\
\text { Líderes de segmento }\end{array}$ & Coeficientes & Erro padrão & Valor-P & $\begin{array}{l}95 \% \\
\text { inferiores }\end{array}$ & $\begin{array}{l}95 \% \\
\text { superiores }\end{array}$ \\
\hline Interseção & 0 & - & $\begin{array}{l}\text { Resposta CM } \\
\text { (Característica de } \\
\text { Metropolização) }\end{array}$ & $\begin{array}{l}\text { Valor das } \\
\text { variáveis }\end{array}$ & $\begin{array}{l}\text { Valor das } \\
\text { variáveis }\end{array}$ \\
\hline$X_{4}$ - Idade & 0,077675 & 0,012901 & $1,34 \mathrm{E}-08$ & 0,052179 & 0,103171 \\
\hline $\begin{array}{l}X_{6} \text { - Renda entre } \\
R \$ 2.365,00 \text { a } R \$ 3.940,00\end{array}$ & 1,16797 & 0,304912 & 0,000189 & 0,565359 & 1,770582 \\
\hline $\begin{array}{l}X_{7} \text { - Renda entre } \\
R \$ 3.941,00 \text { a } R \$ 8.668,00\end{array}$ & 1,123671 & 0,316475 & 0,000518 & 0,498207 & 1,749134 \\
\hline $\begin{array}{l}X_{9} \text { - Escolaridade Superior } \\
\text { Completo }\end{array}$ & 0,79789 & 0,33662 & 0,01908 & 0,132614 & 1,463167 \\
\hline $\begin{array}{l}\text { X10 - Escolaridade Pós- } \\
\text { graduação }\end{array}$ & 0,728989 & 0,335552 & 0,031431 & 0,065822 & 1,392157 \\
\hline
\end{tabular}

Fonte: Dados das entrevistas modeladas pelos autores (2020) e aplicadas ao modelo de regressão linear de Wang, Zhang \& Zheng (2019).

Característica de Metropolização (CM) da região de Passo Fundo e a relação com os municípios que compõem a região, apresentam o resultado da regressão linear, e foi construída a seguinte Equação:

$$
\begin{aligned}
& \mathrm{CM}=0,06963 . \mathrm{Ix}+1,0019 . \mathrm{Rx}_{1}+0,9225 . \mathrm{Rx}_{2}+1,1256 . \mathrm{Scx}+1,0242 . \mathrm{Pgx} \\
& \mathrm{CM}=4,1438
\end{aligned}
$$

em que

$\mathrm{CM}=$ Característica de Metropolização (CM)

$\mathrm{Lx}=$ Idade dos entrevistados

$\mathrm{Rx}_{1}=$ Renda entre $\mathrm{R} \$ 2.365,00$ a $\mathrm{R} \$ 3.940,00$

$\mathrm{Rx}_{2}=$ Renda entre $\mathrm{R} \$ 3.941,00$ a $\mathrm{R} \$ 8.668,00$

Scx = Superior Completo

Pgx = Pós-graduação.

A Equação 1 é resultante da regressão linear, numa escala de 1 a 10, gerando um valor da Característica de Metropolização (CM) de 4,1438. Pelo resultado pode-se afirmar que os líderes de segmento concordam em parte com a metropolização da RMPF, e Passo Fundo como metrópole.

O nível de conhecimento da Característica de Metropolização (CM) está concentrado entre a população que possui o ensino superior completo e os que possuem pós-graduação. Os benefícios do processo de metropolização estão relacionados à possibilidade de acessar políticas públicas específicas ao nível regional, outra questão perpassa pela diminuição das diferenças entre a cidade de Passo Fundo, com as demais cidades, principalmente a diminuição da concentração e centralidade.

A Variável discreta de número inteiro Dummy (Ix) referente à Idade dos entrevistados apresentou um nível elevado em relação à quanto maior idade, maior entendimento e conhecimento sobre o projeto de metropolização, assim como duas as variáveis de Renda. Essa observação pode estar vinculada a alguns fenômenos importantes, dentre eles os movimentos pendulares, que consistem no deslocamento dos residentes de cidades menores à cidade polo, afim de usufruir de atividades relacionadas a trabalho, serviço e lazer. Posteriormente, o retorno a suas cidades de origem. Outro processo significativo é a migração interna, que consiste na mudança de moradia das cidades menores à cidade polo, essas pessoas são atraídas pela possiblidade de maior remuneração e pela diversidade oferecida pela metrópole. 
Na Variável Dummy (Scx) de ensino superior há um nível mais elevado de conhecimento técnico, contudo, possuem proporcionalmente pouco conhecimento sobre a metropolização e as características de Passo Fundo como metrópole. Essa observação pode ser explicada, segundo Moura (2008), através do atual modelo de desenvolvimento regional que mantém o viés concentrador nas cidades polo, acentuando as disparidades regionais, uma vez que continua incluindo territórios funcionais rentáveis e, por outro lado, excluindo os ineficientes ou menos competitivos.

O baixo nível de conhecimento por parte das lideranças a respeito da possibilidade de constituição da RMPF, mesmo existindo marcos regulatórios (Estatuto da Metrópole e PLC 18/2015) e condições objetivas, demonstra que, principalmente em cidades médias, a metropolização requer uma construção política e social. Faz-se necessário um amplo debate com a comunidade, principalmente com as lideranças municipais, com os setores produtivos e formadores de opinião. Caso contrário, mesmo formalmente constituindo uma região metropolitana, possivelmente a criação da RMPF não trará os benefícios esperados e desejáveis à população.

\section{Conclusões}

Por meio dos resultados obtidos na pesquisa, pretende-se confrontar algumas proposições e incoerências que estão presentes no projeto de metropolização da RMPF, nele é prevista a cidade de Passo Fundo como possível sede da região metropolitana. Além disso, destaca-se os pontos positivos e negativos da possibilidade de metropolização.

De maneira teórica, segundo Ribeiro (2012), a metropolização poderia captar outros recursos monetários, por meio de projetos, consórcios, entre outros, que viriam a fortalecer os municípios que fazem parte da região metropolitana. No entanto, Maricato (2011) e Villaça (2012) consideram pouco prováveis os benefícios para a população que está numa distância maior da metrópole e que, além disso, gerariam mais desigualdades sociais e econômicas.

Passo Fundo, historicamente, sempre ocupou um papel de centralidade e, desde o caminho das tropas no século XVII, se estabeleceu algum grau de conectividade com a região, pois os 23 municípios que compõem a RMPF compuseram o território de Passo Fundo em 1857. No caso de uma futura implantação da RMPF, Passo Fundo retomaria sua antiga configuração geopolítica, o que pode mudar a influência de Passo Fundo nos municípios do seu entorno e até mesmo mudar o equilíbrio econômico e social, atualmente consolidados na região.

Em relação à influência regional que Passo Fundo exerce nas atividades econômicas (produtos industriais, educação, saúde, serviços bancários, comércio e empregos) e nas políticas administrativas, pôde-se constatar a existência de dependência de outros municípios para com Passo Fundo, com relação a esses setores.

A partir do processamento dos mapas axiais de integração global, verificou-se a existência de um núcleo central, ou seja, a localização da centralidade na possível RMPF. O município de Passo Fundo aparece com a maior centralidade e com o maior número de conexões do sistema viário, sendo seguido pelos municípios de Carazinho, Mato Castelhano e Coxilha. Esses dados possibilitaram a compreensão dos fluxos do sistema de transporte viário encontram-se integrados com Passo Fundo.

A maior concordância com valor de Conhecimento de Metropolização (CM), de 4,1438 em relação à metropolização da possível RMPF, podem-se destacar a não viabilidade da metropolização, sem que antes tenha havido discussão com os segmentos da indústria, educação, saúde, serviços bancários, comércio, empregos e suas espacializações. Moura et al. (2003) destacam que a maioria das regiões metropolitanas apresentam falta de sustentabilidade institucional, financeira e política, onde a metrópole exerce a principal força produtiva regional. Entretanto, os resultados obtidos expostos neste artigo, ainda são insuficientes para se ter uma conclusão sobre o processo de metropolização definitivo para a RMPF, mas reforça a necessidade de instigar o debate, com a comunidade. Por outro lado, os resultados podem auxiliar a gestão urbana em relação à avaliação e discussão de futuras propostas de metropolização de cidades médias. 


\section{Referências}

Assembleia Legislativa (2015, 5 de fevereiro). Projeto de Lei Complementar n. 18 de 5 fevereiro de 2015. Cria a Região Metropolitana de Passo Fundo Porto Alegre: Rio Grande do Sul: Diário Oficial da Assembleia Legislativa.

Bardin, L. (2016). Análise de conteúdo (3a ed. Vol. 3). São Paulo: Edições 70.

Batistella, A., \& Knack, E. R. J. (2007). Antologia do município de Passo Fundo: a cidade e a região durante os séculos XVII, XVIII e XIX. In Batistella, A. (org.). Passo Fundo sua história (p. 28-63). Passo Fundo: Editora Méritos.

Bernardes, F. L. (2018). Análise urbana a partir dos indicadores capazes de avaliar projetos para condição de metrópole em cidade de porte médio (Dissertação de mestrado). Programa de Pós-Graduação em Arquitetura e Urbanismo, Faculdade Meridional - IMED, Passo Fundo.

Brandão, C. A. (2017). Crise e rodadas de neoliberalização: impactos nos espaços metropolitanos e no mundo do trabalho no Brasil. Cadernos Metrópole, 19(38), 45-69. https://doi.org/10.1590/2236-9996.2017-3802

Brasil (2015, 12 de janeiro). Lei n. 13.089 de 12 de janeiro de 2015. Institui o Estatuto da Metrópole. Brasília: Diário Oficial da União, seções 1 e 2.

Campos, M. V. L. (2019). Os "altos círculos" no mercado de transportes em São Paulo. Urbe. Revista Brasileira de Gestão Urbana, 11, 1-12. http://dx.doi.org/10.1590/2175-3369.011.e20170213

Carmo, J. C. B. do. (2017). Planejamento da Região Metropolitana de Curitiba como objeto de estudo: análise sobre a produção bibliográfica no período de 1974-2006. Urbe. Revista Brasileira de Gestão Urbana, 9(1), 7-18.

http://dx.doi.org/10.1590/2175-3369.009.001.ao01

Clementino, M. do L. M., \& Almeida, L. de. S. B. (2015). Construção técnico-política de governança metropolitana. Cadernos Metrópole, 17(33), 201-224. https://doi.org/10.1590/2236-9996.2015-3309

Clout, H. (2020). Metropole d'Equilibre. International Encyclopedia of Human Geography, 65-71, 2020.

http://dx.doi.org/10.1016/b978-0-08-102295-5.10106-4

Corazza, R., Neckel, A., \& Cambrussi, L. P. (2018). Avaliação das mudanças no uso do solo em áreas rurais no município de Passo Fundo/RS entre 1989 e 2011 com uso de imagens Landsat TM-5. Revista de Arquitetura Imed, 7(1), 68-83. http://dx.doi.org/10.18256/2318-1109.2018.v7i1.2688

Dadashpoor, H., \& Ahani, S. (2019). A conceptual typology of the spatial territories of the peripheral areas of metropolises. Habitat International, 90, 1-15. http://dx.doi.org/10.1016/j.habitatint.2019.102015.

Dadon, J. R., \& Oldani, J. I. (2017). Interjurisdictional coastal management in metropolitan areas. Ocean \& Coastal Management, 148, 260-271. https://doi.org/10.1016/j.ocecoaman.2017.08.002

Ferreira, A. (2016). Caminhando em direção da metropolização do espaço. Geousp: Espaço e Tempo, 20(3), 441-450. https://doi.org/10.11606/issn.2179-0892.geousp.2016.123824

Fuga, T. M. (2019). Análise dos índices de mobilidade urbana das capitais da região sul do Brasil (Dissertação de mestrado). 2019. Programa de Pós-Graduação em Arquitetura e Urbanismo, Faculdade Meridional - IMED, Passo Fundo.

Ghasemi, K., Hamzenejad, M., \& Meshkini, A. (2018). The spatial analysis of the livability of 22 districts of Tehran Metropolis using multi-criteria decision making approaches. Sustainable Cities and Society, 38, 382-404.

http://dx.doi.org/10.1016/j.scs.2018.01.018.

Grub, J., \& Neckel, A. (2015). Arquitetura da hospitalidade: cidade New Babylon e os espaços infraestruturais urbanos. In Anais do XVI ENANPUR (p. 1-17). Belo Horizonte: ENANPUR.

Instituto Brasileiro de Geografia e Estatística - IBGE. (2018). Regiões de Influência das Cidades. Rio de Janeiro: IBGE.

Recuperado em 12 de janeiro de 2018, de www.ibge.gov.br

Instituto Brasileiro de Geografia e Estatística - IBGE. (2020). Censo Demográfico - 2010. Rio de Janeiro: IBGE. Recuperado em 26 de fevereiro de 2020, de www.ibge.gov.br

Hoshino, T. de A. P., \& Moura, R. (2019). Politizando as escalas urbanas: jurisdição, território e governança no Estatuto da Metrópole. Cadernos Metrópole, 21(45), 371-392.

Hillier, B. (2007). Space is the machine: a configurational theory of architecture (1a ed., Vol. 5). Heneage Street London: United Kingdom. 
Jaeger, S. R., Vidal, L., Kam, K., \& Ares, G. (2017). Can emoji be used as a direct method to measure emotional associations to food names? Preliminary investigations with consumers in USA and China. Food Quality and Preference, 56, 38-48. http://dx.doi.org/10.1016/j.foodqual.2016.09.005

Jayasinghe, A., Sano, K., \& Rattanaporn, K. (2017). Application for developing countries: Estimating trip attraction in urban zones based on centrality. Journal of Traffic and Transportation Engineering, 4(5), 464-476.

https://doi.org/10.1016/j.jtte.2017.05.011

Karimi, K. (2017). Space syntax: consolidation and transformation of an urban research field. Journal of Urban Design, 23(1), 1-4. https://doi.org/10.1080/13574809.2018.1403177

Kujawa, H. A. (1998). Formação étnica de Passo Fundo e região: Passo Fundo: uma história, várias questões (1a ed., Vol. 1). Passo Fundo: EDIUPF.

Lansdall-Welfare, T., Sudhahar, S., Thompson, J., Lewis, J., \& Cristianini, N. (2017). Content analysis of 150 years of British periodicals. Proceedings of The National Academy of Sciences, 114(4), 1-9. http://dx.doi.org/10.1073/pnas.1606380114

Li, Q., Zhou, S., \& Wen, P. (2019). The relationship between centrality and land use patterns: empirical evidence from five chinese metropolises. Computers, Environment and Urban Systems, 78, 1-13.

http://dx.doi.org/10.1016/j.compenvurbsys.2019.101356

Lobo, M. A. A., Tourinho, H. L. Z., \& Costa, É. F. N. da. (2017). Urbanização, dispersão urbana e estrutura intraurbana de cidades intermediárias da Amazônia: o caso de Altamira (PA). Boletim de Geografia, 35(1), 43-63.

https://doi.org/10.4025/bolgeogr.v35i1.30668

Maculan, L. S., \& Tângari, V. R. (2020). Elementos estruturadores do território e os efeitos na borda urbana de Passo Fundo/RS. Revista Nacional de Gerenciamento de Cidades, 8(57), 18-35. https://doi.org/10.17271/2318847285720202284

Maricato, E. (2011). Brasil, cidades: alternativas para a crise urbana (5a ed., Vol. 1). Petrópolis: Vozes.

Martínez, C. F., \& Santibáñez, N. W. (2015). Movilidad femenina en Santiago de Chile: reproducción de inequidades en la metrópolis, el barrio y el espacio público. Urbe. Revista Brasileira de Gestão Urbana, 7(1), 48-61.

http://dx.doi.org/10.1590/2175-3369.007.001.ao03

Meyer, M. A. (2017). Elderly Perceptions of Social Capital and Age-Related Disaster Vulnerability. Disaster Medicine and Public Health Preparedness, 11(1), 48-55. https://doi.org/10.1017/dmp.2016.139

Moura, R. (2008). Arranjos urbano-regionais: uma categoria complexa na metropolização brasileira. Revista Brasileira de Estudos Urbanos e Regionais, 10(2), 29-30.

Moura, R., Libardi, D., \& Barion, M. I. Institucionalização de regiões metropolitanas: qual o sentido? Revista Paranaense de Desenvolvimento, 111, 129-143.

Moura, R., Delgado, P. R., Deschamps, M., \& Cardoso, N. A. (2003). Brasil Metropolitano: uma configuração heterogênea. Revista Paranaense de Desenvolvimento, 105, 33-56.

Neckel, A. (2014). A questão ambiental nos cursos de Geografia do Brasil e o pensamento geográfico sobre a concepção de ambiente (Tese de doutorado). Programa de Pós-Graduação em Geografia, Universidade Federal do Rio Grande do Sul, Porto Alegre.

Nunes, D. B. (2016). Proposição de um modelo de regressão linear para avaliação do valor de mercado de apartamentos residenciais (Dissertação de mestrado). Programa de Pós-Graduação em Engenharia Civil: Estruturas e Construção Civil, Universidade Federal do Ceará, Fortaleza.

Ojima, R., Monteiro, F. F., \& Nascimento, T. C. L. (2015). Urbanização dispersa e mobilidade no contexto metropolitano de Natal: a dinâmica da população e a ampliação do espaço de vida. Urbe. Revista Brasileira de Gestão Urbana, 7(1), 9-20. 2015

Ojima, R. (2006). A produção e o consumo do espaço nas aglomerações urbanas brasileiras: desafios para uma urbanização sustentável. In Anais do XV Encontro Nacional de Estudos Populacionais (p. 1-19). São Paulo: ABEP.

Ossandón, A. M. O., Lanata, P. B., Arce, L. A. F., Peralta, H. G., \& Casale, K. P. (2013). Huellas del proceso de metropolización en Chile. Revista Invi, 28(77), 17-66. http://dx.doi.org/10.4067/s0718-83582013000100002

PERES, J. L. P., Adriano, H. S. R., Seraphim, A. P. A. C. C., \& Olalquiaga, A. A. (2018). O Estatuto da Metrópole e as regiões metropolitanas: uma análise teórico-conceitual à luz do conceito miltoniano de "território usado". Cadernos Metrópole, 20(41), 267-288. 
Prunzel, J., Toebe, M., Lopes, A. B., \& Moreira, V. S. (2016). Modelos de regressão linear múltipla aplicados à avaliação de terrenos urbanos - caso do município de Itaqui-RS. Boletim de Ciências Geodésicas, 22(4), 651-664.

http://dx.doi.org/10.1590/s1982-21702016000400037

Raposo, I. S., Jorge, S., Viegas, S., \& Melo, V. (2012). Luanda e Maputo: inflexões suburbanísticas da cidade socialista à cidade-metrópole neoliberal. Urbe - Revista Brasileira de Gestão Urbana, 4(446), 189-205.

http://dx.doi.org/10.7213/urbe.7395

Reis, N. G. (2006). Notas sobre urbanização dispersa e novas formas de tecido urbano (1a ed., Vol. 1). São Paulo: Via das artes.

Ribeiro, L. C. de Q. (2012). As metrópoles brasileiras no milênio: resultados de um programa de pesquisa (1a ed., Vol. 1). Rio de Janeiro: Letra capital.

Rosaneli, A. F., Fróes, A. C. S., Furlan, D. L. S., Gonçalves, F. T., \& Senger, S. (2016). Apropriação do espaço livre público na metrópole contemporânea: o caso da Praça Tiradentes em Curitiba/PR. Urbe. Revista Brasileira de Gestão Urbana, 8(3), 359-374. http://dx.doi.org/10.1590/2175-3369.008.003.ao06

Rückert, A. A. (2007). Metamorfoses do território. A agricultura de trigo/soja no planalto médio rio-grandense, 1930/1990 (9a ed., Vol. 9). Porto Alegre: UFRGS.

Ruiz, C. A. (2015). Metropolización y gobernanza económica: bases para una propuesta de análisis económico. Suma de Negocios, 6(13), 52-65. http://dx.doi.org/10.1016/j.sumneg.2015.04.003

Sá, R. A. M. de., Carvalho, A. L. S., Barbosa, Y. M., Barsch, B., \& Araðjo Filho, A. R. de. (2017). Estatuto da Metrópole: a governança interfederativa. Urbe. Revista Brasileira de Gestão Urbana, 9(2), 203-215. http://dx.doi.org/10.1590/21753369.009.002.ao04

Santos, A. M. S. P. (2010). Urbanização brasileira: um olhar sobre o papel das cidades médias na primeira década do século XXI. RBEUR. Revista Brasileira de Estudos Urbanos e Regionais, 12(2), 103-119. http://dx.doi.org/10.22296/2317$1529.2010 \mathrm{v} 12 \mathrm{n} 2 \mathrm{p} 103$

Scott, A. J. (2019). City-regions reconsidered. Environment and Planning A: Economy and Space, 51(3), 554-580. http://dx.doi.org/10.1177/0308518x19831591.

Silva, M. V. G., Peron, A. C. P., Meza, M. L. F. G., Nascimento, D. E., \& Sacoman, C. (2018). A governança metropolitana e o desafio da integração na lei no 13.089/2015. Urbe. Revista Brasileira de Gestão Urbana, 10(1), 186-198.

http://dx.doi.org/10.1590/2175-3369.010.001.ao13

Srinurak, N., \& Mishima, N. (2017). Urban Axis and City shape evaluation through spatial configuration in 'Lan Na' Northern Thailand Historic city. City, Territory and Architecture, 4(1), 1-18. http://dx.doi.org/10.1186/s40410-017-0067-z

Tedesco, J. C. (2002). Madeireiros, Comerciantes e Granjeiros: lógicas e contradições no processo de desenvolvimento socioeconômico de Passo Fundo (1900-1960) (1a ed., Vol. 1). Porto Alegre: EST Edições.

Teixeira, J. S., Stutz, L. T., Knupp, D. C., \& Silva Neto, A. J. (2020). A new adaptive approach of the Metropolis: Hastings algorithm applied to structural damage identification using time domain data. Applied Mathematical Modelling, 82, 587606. http://dx.doi.org/10.1016/j.apm.2020.01.021

USGS. United States Geological Survey (2018). Remote Sensing and Landsat. Recuperado em 10 de setembro de 2019, de https://www.usgs.gov

Villaça, F. (2012). La estructura urbana de Buenos Aires. RBEUR. Revista Brasileira de Estudos Urbanos e Regionais, 14(1), 167-185. http://dx.doi.org/10.22296/2317-1529.2012v14n1p167

Zhu, H., Liu, J., Liu, H., Wang, X., \& Ma, Y. (2017). Recreational Business District boundary identifying and spatial structure influence in historic area development: a case study of Qianmen area, China. Habitat International, 63, 11-20. http://dx.doi.org/10.1016/j.habitatint.2017.03.003

Wang, Z., Zhang, H., \& Zheng, H. (2019). Estimation of Lorenz curves based on dummy variable regression. Economics Letters, 177, 69-75. http://dx.doi.org/10.1016/j.econlet.2019.01.021

Editor: Rodrigo Firmino

Recebido: 11 maio 2020

Aprovado: 11 jan. 2021 